\title{
A microstructure insight into the water retention properties of the Callovo- Oxfordian claystone
}

\author{
Hamza Menaceur ${ }^{1,2}$, Pierre Delage ${ }^{1, a}$, Anh Minh Tang ${ }^{1}$ and Jean Talandier ${ }^{3}$

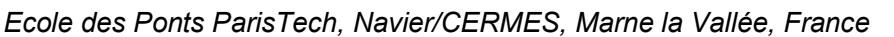

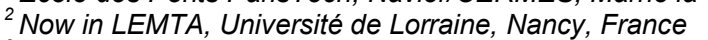

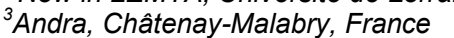

\begin{abstract}
The effect of changes in suction on the microstructure of the Callovo-Oxfordian claystone along wetting and drying paths was investigated by using mercury intrusion porosimetry. Based on a simplified brick model, the changes of the average thickness of the platelets that constitute the clay matrix (50\%) are interpreted as the consequence of the successive adsorption of ordered layers of water molecules along the smectite surfaces, as demonstrated on pure smectites for a long time. This shows the predominant role played by the smectite phase in the overall response of the Callovo-Oxfordian claystone when submitted to suction changes under no stress.
\end{abstract}

\section{Introduction}

The Callovo-Oxfordian (COx) claystone is considered as a possible host rock for deep geological disposal of radioactive waste in France. To better investigate its hydromechanical properties, many investigations are carried in the Underground Research Laboratory (URL) mnaged by Andra (the French Agency for radioactive waste disposal) close to the village of Bure (Eastern France). The URL has been excavated at a depth of 490 $\mathrm{m}$ in a $150 \mathrm{~m}$ thick layer COx claystone. Many investigations are also carried out in surface research laboratories.

Desaturation of specimens of the COx claystone occur in-situ in the gallery walls due to ventilation. Also, the specimens cored appear to be desaturated due to the combined effects of stress release, and evaporation occurring during the successive phases of transport, storage and also preparation and trimming of the specimens for testing.

Claystones are known to be very sensitive to changes in water content, with significant increase in mechanical properties (stiffness and shear strength) with decreased water content and degree of saturation (e.g. Pham et al., 1). The water retention properties of the COx claystone have been investigated in detail in Wan et al. (2) who also evidenced some mechanisms governing volume changes and swelling.

In this paper, the investigation of the water retention properties of the COx specimen is completed by that of the changes in microstructure examined by using mercury intrusion porosimetry tests on freeze-dried specimens. To do so, MIP tests were carried out on specimens previously brought at various suctions, starting from the initial state. Particular attention is paid to the role played by the smectite fraction within the clay matrix that is typical from the COx claystone.

\section{The Callovo-Oxfordian claystone}

The COx claystone is a sedimentary rock deposited 155 millions years ago on top of a layer of Dogger limestone that was afterwards covered by an Oxfordian limestone layer. The COx claystone is composed of a clay matrix containing some detritic grains of quartz and calcite. At the depth of the Bure URL $(490 \mathrm{~m})$, the average mineralogical composition of COx claystone is as follows (Gaucher et al., 3): $45-50 \%$ clay fraction (mainly interstratified minerals of illite-smectites with a fraction between 50 and $70 \%$ of smectites, $20 \%$ carbonate, $22 \%$ quartz and $9 \%$ other minerals (feldspars, pyrite, dolomite and siderite). The total porosity varies in the $\mathrm{COx}$ layer between $14 \%$ in carbonated levels and $19.5 \%$ in the more argillaceous levels (Yven et al., 4).

The specimens were drilled from a $80 \mathrm{~mm}$ diameter and $300 \mathrm{~mm}$ long core (EST44584) parallel to bedding that was extracted at the level the URL $(490 \mathrm{~m})$. The water content was determined after drying in the oven at $105{ }^{\circ} \mathrm{C}$ for 48 hours. The porosity and degree of saturation were calculated from carefully measuring the sample volume by using hydrostatic weighing. The initial total suction was determined by using a dew point tensiometer (WP4, Decagon).

The specimens EST44584 appeared to be not fully saturated at initial state with a degree of saturation around $77.6 \%$ corresponding to a suction of $34 \mathrm{MPa}$ for a porosity of $17.0 \%$. The dry density and grain density values are 2.16 and $2.7 \mathrm{Mg} / \mathrm{m}^{3}$, respectively. Partial

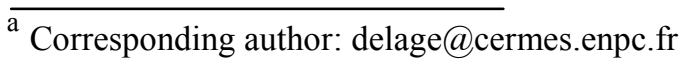


saturation resulted from the combined actions of coring, transport, storage and specimen preparation.

\section{Experimental methods}

\subsection{Water retention curve}

The determination of the water retention properties of the COx claystone was carried out by controlling suction through the vapour phase. This technique consists in placing the specimens (disks of $38 \mathrm{~mm}$ in diameter and $10 \mathrm{~mm}$ in height) into desiccators containing saturated saline solutions (Table 1).

Table 1. Saturated solutions used

\begin{tabular}{|l|c|c|}
\hline Solution & $\begin{array}{c}\text { Relative humidity } \\
(\%)\end{array}$ & Suction (MPa) \\
\hline $\mathrm{KOH}$ & 9 & 331 \\
\hline $\mathrm{MgCl}_{2}$ & 33 & 150 \\
\hline $\mathrm{KNO}_{3}$ & 93.7 & 9 \\
\hline Pure water & 100 & 0 \\
\hline
\end{tabular}

There is no confinement on the sample that is free to swell or shrink. Specimens were left in the desiccators until reaching mass stabilization (checked by periodic precision weighing). Once equilibrated, a suction measurement was made by using the WP4 dew point potentiometer to confirm the achievement of the desired value of suction. Afterwards, the specimens were immediately waxed using slush wax (at lowest possible temperature before solidification, see Wan et al. (2) for more detail). Careful weighing was carried out prior and after waxing, giving a good determination of the wax weight and volume. The specimen volume was obtained by subtracting the wax volume from that of the waxed specimen. The wax technique was also used to obtain the specimen volume at initial state $(34 \mathrm{MPa}$ of suction, degree of saturation of $77.6 \%$ ). Finally, the specimens were cut into small pieces to measure their water content by oven drying. The void ratio and degree of saturation were determined by measuring the volume by means of hydrostatic weighing.

\subsection{Microstructure investigation}

Mercury intrusion porosimetry tests were conducted on various specimens at different suctions along the drying or wetting paths followed. To preserve the microstructure, dehydration was made by freeze-drying small pieces of claystone (1-3 g in weight) that were previously quickly frozen by immersion in slush nitrogen $\left(-210^{\circ} \mathrm{C}\right)$. Fast immersion in slush nitrogen is preferable because no boiling occurs around the specimen, resulting in faster freezing of water with no volume change (see Delage et al., 5). MIP tests were carried out in a Micromeritics-AutoPore IV 9500 porosimeter from a low initial pressure of $3.4 \mathrm{kPa}$ up to $227.5 \mathrm{MPa}$, corresponding to entrance pore diameters of $363.6 \mu \mathrm{m}$ and $5.5 \mathrm{~nm}$ respectively.

The intruded mercury porosity $\left(n_{H g}\right)$ was defined as the ratio of mercury intrusion volume $V_{H g}$ to specimen total volume $V$ :

$$
n_{H g}=\frac{V_{H g}}{V}
$$

The pore entrance diameter $(D)$ was determined from the intrusion pressure $P_{H g}$ by assuming a cylindrical pore shape according to the Laplace-Young equation:

$$
D=\frac{4 \sigma \cos \theta}{P_{H g}}
$$

where $\sigma$ is the mercury-solid interfacial tension and $\theta$ is the mercury-solid contact angle $(\sigma=0.484 \mathrm{~N} / \mathrm{m}$ and $\theta$ $=141.3^{\circ}$ according to Diamond, 6).

\subsection{Experimental program}

A first series of samples were submitted to dryingwetting path from the initial water content $(6.12 \%$ with a $34 \mathrm{MPa}$ suction and $S_{r}=77.6 \%$ ). Two specimens were simultaneously dried under suctions of 150 and $331 \mathrm{MPa}$ along the drying path, to check repeatability. Specimens A1 and B1 were used to define the specimen characteristics and to investigate their microstructure at 150 and $331 \mathrm{MPa}$ respectively. Once dried at $331 \mathrm{MPa}$, specimens A2 and B2 were afterwards wetted at $9 \mathrm{MPa}$ and zero suctions, so as to determine the main wetting path. Along the wetting path, both specimens were periodically taken out from the desiccator for weighing so as to determine their water content. Their suction was also measured by means of the WP4 dew-point tensiometer.

A second series of tests corresponds to wetting-drying paths. Starting from the initial water content $(6.12 \%)$, three other specimens (C, D1 and D2) were firstly wetted under decreasing suctions ( $9 \mathrm{MPa}$ for specimen $\mathrm{C}$ and zero suction for specimens D1, D2). Specimen D2 was then used to determine the main drying path up to suctions of $150 \mathrm{MPa}$ and $331 \mathrm{MPa}$.

\section{Water retention properties}

The water retention curve expressed in terms of changes in water content versus suction is presented in Figure 1 (zero suction arbitrarily plotted at $0.01 \mathrm{MPa}$ ). Starting from initial state $(\mathrm{w}=6.12 \%$, suction $34 \mathrm{MPa})$, two points were obtained from two distinct specimens with a direct single step drying at controlled suctions of 150 and $331 \mathrm{MPa}$, respectively. Similarly, two other points were obtained with a direct single step wetting at suctions of 9 and $0 \mathrm{MPa}$. Data along the main wetting and drying paths were also obtained by suction measurements and water content determination along the wetting path from 331 to $0 \mathrm{MPa}$ for specimen B2 and along the drying path from zero suction to $331 \mathrm{MPa}$ for specimen D2. Good correspondence is observed along the main wetting path between the data of specimens B2 and A2 that was 
wetted between 331 and $9 \mathrm{MPa}$, providing some confidence in the quality of the data.

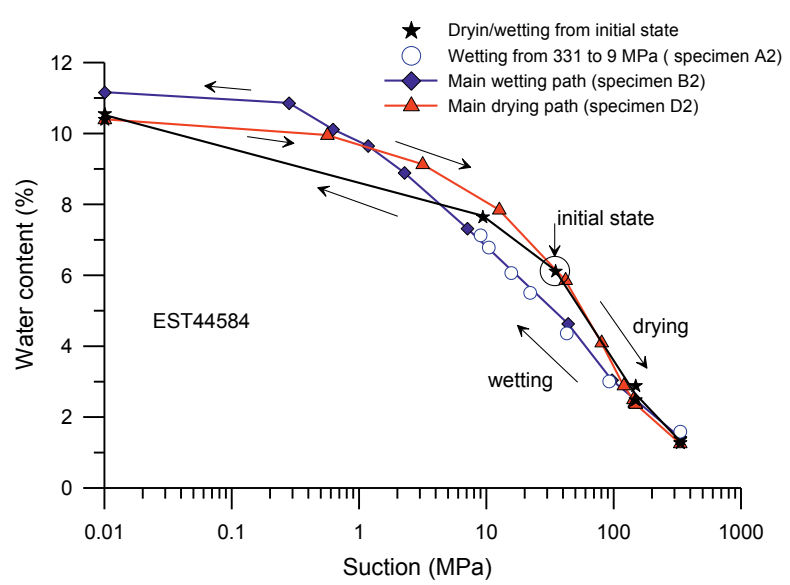

Figure 1. Water retention curve

Examination of the main drying and wetting paths shows that the water retention properties of the $\mathrm{COx}$ claystone are characterized, commonly, by a hysteresis effect. The data also show that the initial state resulting from desaturation from the in-situ saturated state is located, as expected, on the main drying path.

The wetting path starting from the initial state shows that the point at $9 \mathrm{MPa}$ of suction (specimen $\mathrm{C}$ ) is located below the main drying path, which is typical of scanning curves (there is unfortunately no other point between 9 $\mathrm{MPa}$ and zero suction along this path). The point at zero suction obtained along the main wetting path starting from the dry state at $331 \mathrm{MPa}$ provides a water content $(11.2 \%)$ higher than that obtained after wetting the specimen from the initial water content $(10.4 \%)$. This is due to the longer period of time waited for ( 90 days for B2 compared to 40 days for D1 and D2.

The changes in degree of saturation with suction and water content are presented in Figure 2 and Figure 3

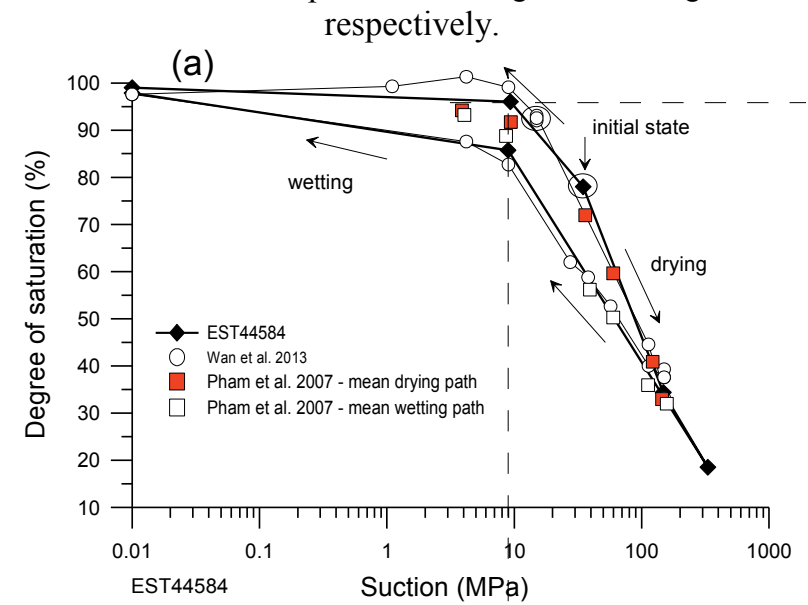

Figure 2. Change in degree of saturation with respect to suction

The data taken from similar tests by Pham et al. (1) and by Wan et al. (2) are also plotted in Figure 2, with good agreement between the data.

The specimen following the wetting path from the initial state comes close to saturation at $9 \mathrm{MPa}\left(S_{r}=96 \%\right.$, $w=7.65 \%$ ). At suction smaller than $9 \mathrm{MPa}$, the significant increase observed in water content occurs in saturated condition. Along the drying path from initial state, a linear relationship is observed between $S_{r}$ and $w$ with an average decrease of $13 \%$ in $S_{r}$ for a decrease of $1 \%$ in $w$. The main wetting curve obtained once the specimen dried at the highest suction $(331 \mathrm{MPa})$ is located below the curves of drying-wetting from initial state, confirming the hysteresis observed by Wan et al. (2).

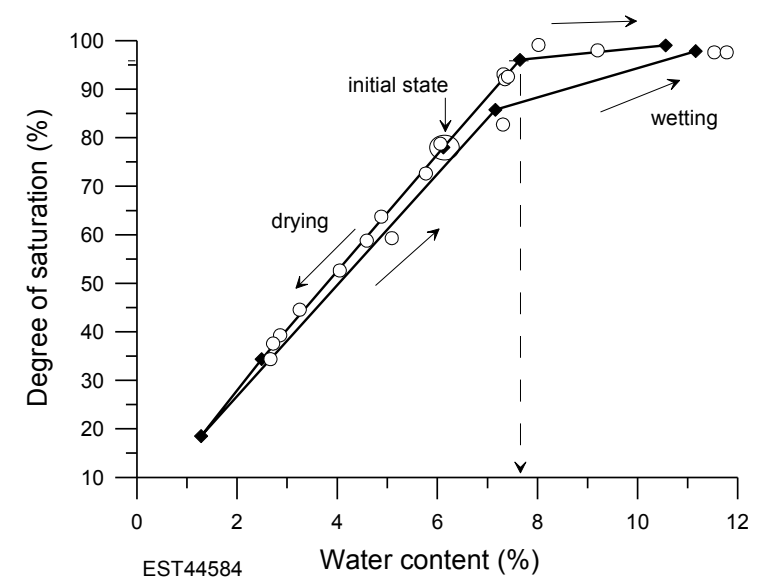

Figure 3. Change in degree of saturation with respect to water content

The volume changes with respect to suction (Figure 4) show that drying from initial state to $331 \mathrm{MPa}$ results in a shrinkage of $2.0 \%$ while wetting to zero suction induces a swelling strain of $6.1 \%$.

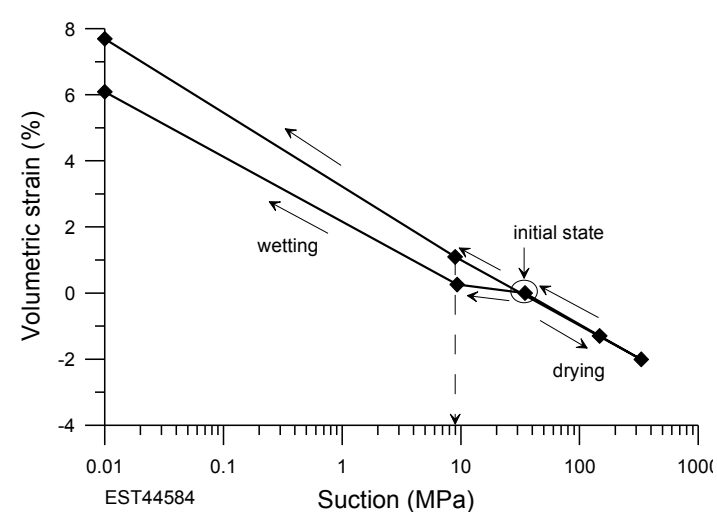

Figure 4. Volume changes with respect to water content

Figure 4 also shows that reducing suction along the wetting path from initial state occurs with little swelling $(0.3 \%)$ from 34 to $9 \mathrm{MPa}$ followed by significant swelling below $9 \mathrm{MPa}(6.1 \%$ at zero suction) that occurs within a saturated specimen, as commented above. The specimen previously dried up to $331 \mathrm{MPa}$ before wetting to zero suction (main wetting path) is not brought back to the same point as that of the specimen submitted to a wetting path from initial state, with some irreversible swelling strain $(1.6 \%)$ and higher volume at zero suction. However, the main wetting path is close to the drying curve from initial state at higher suction ( $>40 \mathrm{MPa}$ ) showing some reversibility in the volume change behaviour under stress free conditions at highest suctions. 


\section{Pore size distributions}

The results of the MIP test obtained at initial state $\left(S_{r}=\right.$ $77.6 \%$, porosity $n=17.0 \%$ ) are presented in Figure 5a in cumulative plot and Figure $\mathbf{5 b}$ in a density function plot. The total porosity $n$ of the specimen is also plotted in the cumulative curve, showing that the mercury intruded porosity $n_{H g}$ is smaller than the total one, with an infraporosity $n-n_{H g}$ of $4 \%$. Pores smaller than the lower limit of $5.5 \mathrm{~nm}$ (corresponding to the maximum mercury pressure of $227.5 \mathrm{MPa}$ ) cannot be intruded.

The density function exhibits a typical monomodal curve with a well defined pore population identified by an inflection point at $32 \mathrm{~nm}$ defining the average entrance pore diameter within the clay matrix.
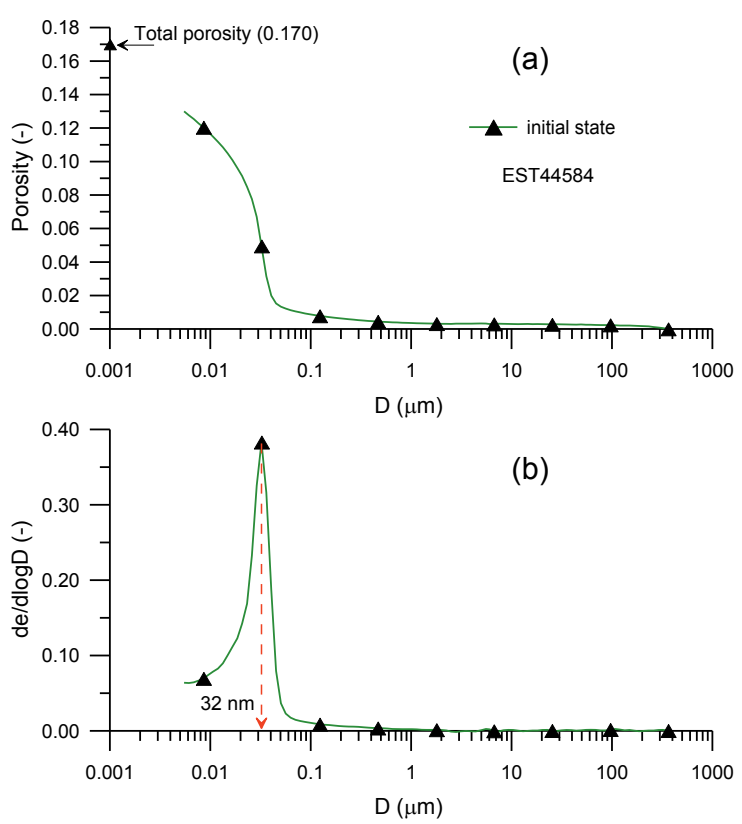

Figure 5. Pore size distribution, initial state

Figure 6 presents an enlargement between 0.001 and 0.1 $\mu \mathrm{m}$ of the PSD curves of specimens A1 and B2 dried at 150 and $331 \mathrm{MPa}$ respectively from the initial state, together with the PSD data of specimens at initial state and oven-dried at $105^{\circ} \mathrm{C}$ during $48 \mathrm{~h}$. The total porosities are also given. The infra-porosities not intruded by mercury $(D<5.5 \mathrm{~nm})$ are again lower than the total ones. They are smaller than that at initial state $\left(n-n_{H g}=3.0 \%\right.$ for specimens dried up to 150 and $331 \mathrm{MPa}$, compared to $4 \%$ at initial state). Conversely, the mercury intruded porosity of the oven-dried specimen $(12 \%)$ appears to be quite close to the total one (13\%) giving an infra-porosity $n-n_{H g}=1 \%$ significantly smaller than at suctions of 150 and $331 \mathrm{MPa}(3 \%)$.

The degree of saturation of each specimen is also reported in Figure 6, based on the hypothesis that water is contained in smaller pores due to the nature of both physico-chemical clay water interactions and capillary effects. The arrows indicate the maximum diameter of the pores saturated by water. One can observe that the main pore population is almost saturated (up to a diameter of $33 \mathrm{~nm}$ ) at initial state (suction $34 \mathrm{MPa}, S_{r}=77.6 \%$, mean radius $32 \mathrm{~nm}$ ) whereas this population becomes full of air at $150 \mathrm{MPa}$ suction and $S_{r}=34.4 \%$ with reduction of the mean radius at $28 \mathrm{~nm}$ and with the largest saturated pore having a diameter of $13 \mathrm{~nm}$.
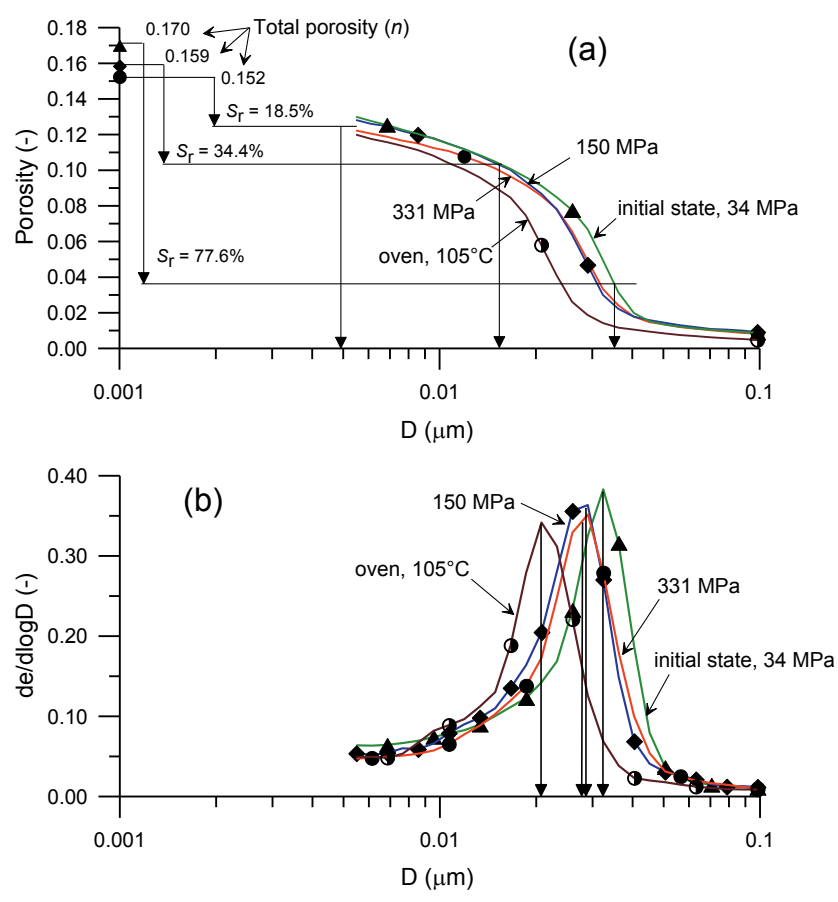

Figure 6. Pore size distributions, dried states

At $331 \mathrm{MPa},\left(S_{r}=18.5 \%\right)$, the largest saturated pore has a diameter of around $4.9 \mathrm{~nm}$ with however no significant change in the mean radius value that slightly decreases to $27 \mathrm{~nm}$. In other words, the desaturation of pores between 13 and $4.9 \mathrm{~nm}$ does not significantly affect the microstructure at the level of both the mean pore population and of the infra-porosity that remains constant (3\%). Conversely, the effect of oven-drying is much stronger than drying at 150 and $331 \mathrm{MPa}$ suctions, with a reduction of the mean pore diameter to $21 \mathrm{~nm}$ and, more importantly, a significant reduction of the infra-porosity to $1 \%$. There is obviously a gap between the highest applied suction (331 MPa) and the total removal of water from the microstructure by oven-drying. Note that the 21 $\mathrm{nm}$ mean pore diameter obtained on the oven-dried specimen is comparable to the values obtained by Sammartino et al. (7) and Boulin et al. (8) on oven-dried specimens (respectively dried at 105 and $70^{\circ} \mathrm{C}$ ).

In Figure 7, the pore size distribution curves of the two specimens wetted from initial state at low suctions (9 $\mathrm{MPa}$ and zero) and higher degree of saturation ( $S_{r}=96 \%$ and $99 \%, s=9$ and $0 \mathrm{MPa}$, respectively) are presented together with the data at initial state $\left(S_{r}=\right.$ $77,6 \%, s=34 \mathrm{MPa}$ ). Also plotted in the Figure are the total porosities of the specimens.

The PSD cumulative and density function curves at 9 MPa suction $\left(S_{r}=96 \%\right)$ are quite similar to that at initial state with a only slight increase in total porosity at $9 \mathrm{MPa}$ $(0.2 \%)$, showing that the infra-porosity is also similar in both cases. This is compatible with the negligible volume change observed in the curve of Figure 4. The specimen saturation from $S_{r}=78 \%$ to $96 \%$ hence occurs by complete filling of the mean pore population with very 
little microstructure changes both in the porosity intruded and not intruded by mercury.
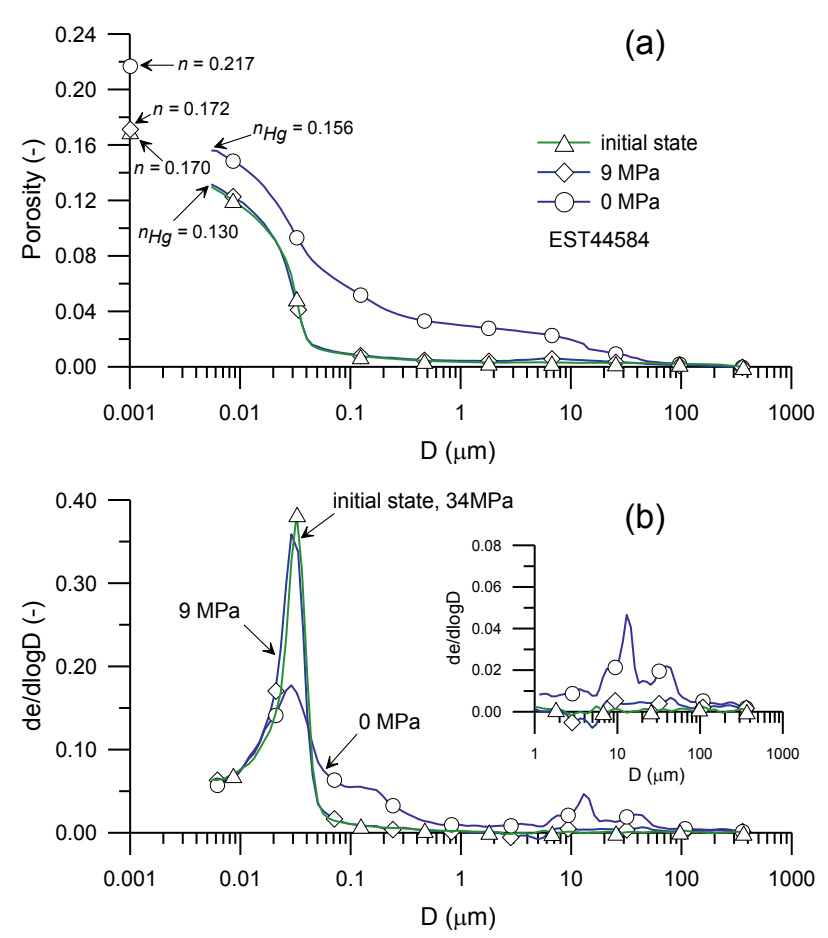

Figure 7. Pore size distributions, wetted states

The reduction in suction from $9 \mathrm{MPa}$ to $0 \mathrm{MPa}$ occurs at quasi-saturated state (see Figure 3) with significant $6.1 \%$ swelling giving a final water content of $10.5 \%$ and degree of saturation of $99 \%$. Significant changes are also observed at the microstructure level, with a bimodal PSD curve at $0 \mathrm{MPa}$. Changes affect three levels of porosity:

- i) The infra porosity $n-n_{H g}$ that increases from $4 \%$ at 9 MPa to $6.1 \%$ at zero suction with an intruded porosity of $15.6 \%$ and a total one of $21.7 \%$;

- ii) The large porosity with appearance of a new pore population corresponding to a proportion of $10.5 \%$ of the total porosity in the range of diameters between 7 and $100 \mu \mathrm{m}$ with a mean diameter around $12 \mu \mathrm{m}$;

- iii) An enlargement of the previous pore population that moves from a narrow range between 12 and $50 \mathrm{~nm}$ to a wider range between 12 and $500 \mathrm{~nm}$ with a new plateau between 60 and $200 \mathrm{~nm}$.

Note however that no change is observed in the density function curves between 5 and $20 \mathrm{~nm}$.

\section{Discussion}

Microstructure changes with respect to suction changes are interpreted based the conceptual model of the COx claystone microstructure proposed by Yven et al. (2007) and presented in Figure 8. The model schematically shows how individual calcite or quartz detritic grains are embedded into a clay matrix with porosity that represents $45-50 \%$ of total constituents at the depth of $490 \mathrm{~m}$ considered here.

The interpretation of the well defined single pore population defined by an average value of $32 \mathrm{~nm}$ observed in the PSD curve of Figure 5 can be made by assimilating the clay matrix to an assembly of bricks made up of platelets of comparable thickness, as seen in Figure 8. The mean pore radius hence provides an estimate of the average platelet thickness.

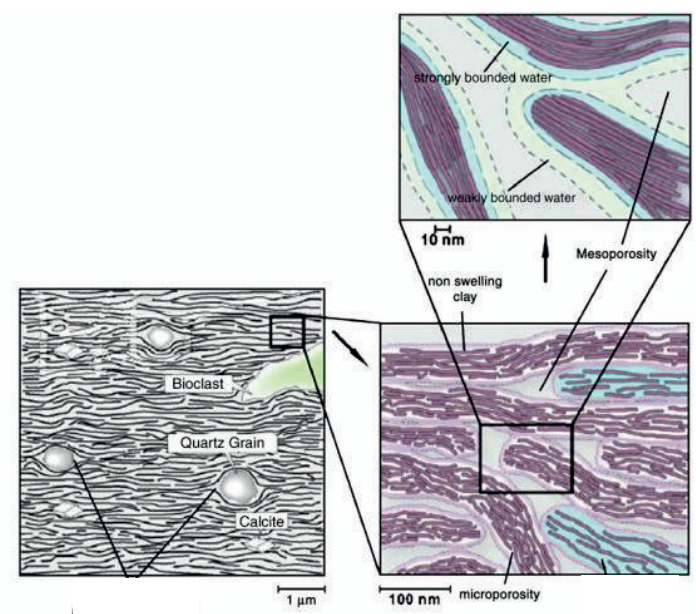

Figure 8. Microstructure model (after Yven et al., 4)

The change in PSD curves is now interpreted based on the mechanisms of hydration of smectites, which, based on the results of X-Ray diffraction investigations, is known for some time to occur by the ordered and successive placement of layers of water molecules along the clay layers, depending of the suction (e.g. Mooney et al., 9). Typically, the first layer is observed at high suctions of various hundreds of MPa, whereas the second one is observed under various tens of $\mathrm{MPa}$ and the third one below around $9 \mathrm{MPa}$ (see also Saiyouri et al., 10). XRay diffraction investigations also showed that, starting from a inter-basal spacing of $9.6 \AA$ for illite and smectite, inter-basal spacings of $12,5,15,5$ and $18,5 \AA$ corresponded to the hydrated states of smectite with 1,2 and 3 layers of water molecules, respectively. This adsorption occurs at the inter-layer level, within the clay platelets represented in the scheme of Figure 8. It hence affects the average thickness of the platelets that we detect here by measuring the average entrance pore radius within the clay matrix.

Observation of the PSD curves of Figure 6 indicates that drying is characterized by a reduction of the mean diameter of the single pore population from $32 \mathrm{~nm}$ (intact) to $28(150 \mathrm{MPa}), 27(331 \mathrm{MPa})$ and $21 \mathrm{~nm}$ (ovendried). Based on the brick model, this corresponds to a reduction in thickness of the bricks, i.e. of the platelets. This reduction is only due to changes in the interlayer spacing of smectite, given that illite minerals are not sensitive to changes in water content. The reduction of the average diameter from $32 \mathrm{~nm}$ (initial state) to 28$27 \mathrm{~nm}$ when passing from $34 \mathrm{MPa}$ to $150-331 \mathrm{MPa}$ can then be linked to the transition from two (inter-basal spacing of $15.6 \AA$ ) to one adsorbed layer of water molecules (inter-basal spacing of $12.6 \AA$ ).

Oven drying results in having no more water layer adsorbed. At dry state (interlayer spacing of $9.6 \AA$ for smectites and illites) and with an average platelet thickness of $21 \mathrm{~nm}$ as obtained from the PSD curve of Figure 6, an average number of 22 layers by platelets can be roughly estimated. Considering the proportion of 50- 
$70 \%$ smectite minerals provided by Yven et al. (4) at the $490 \mathrm{~m}$ depth in the COx layer, one can conclude that the introduction of one water layer along the smectite layers would result in the placement of between 11 and 15 layers of $3 \AA$ thick layers of water molecules, resulting in an increase in the platelet thickness between 3,3 and of $4,6 \mathrm{~nm}$, from 21 to $24,3-25,6 \mathrm{~nm}$. This is not far from the $28 \mathrm{~nm}$ value measured by MIP under suctions of 150 and $331 \mathrm{MPa}$. Adding another water layer would then provide a thickness between 27,6 and $30.2 \mathrm{~nm}$, reasonably comparable to the $32 \mathrm{~nm}$ measured by MIP under 34 and $9 \mathrm{MPa}$ suctions.

This indicates that the analysis based on the step hydration process evidenced in pure and compacted smectites is reasonably compatible with the analysis of the MIP data with respect to the changes in platelets thickness in the COx clay matrix with suction. Better fitting is actually obtained with the higher proportion of smectite of $70 \%$ in the clay fraction. The mechanism of hydration of smectites hence appears to be of significant interest to interpret the water retention properties and related microstructure changes of the $\mathrm{COx}$ claystone.

\section{Conclusion}

Better understanding of the changes in microstructure that occur along the wetting and drying paths of the water retention curve of the COx claystone have been gained through a microstructure study carried out by using MIP.

Some further information on the water retention properties was obtained from monitoring volume changes, showing significant swelling at saturated state at suction lower than $9 \mathrm{MPa}$ through the hydration and development of saturated cracks.

The concepts developed to describe the hydration mechanisms of smectites and their dependency with respect to suction changes appear to be applicable to the hydration of the mixed-layer illite-smectite minerals that play a predominant role with respect to changes in water content and the swelling-shrinkage behaviour of the COx claystone. Releasing the suction to $9 \mathrm{MPa}$ results in the saturation of the claystone but does not significantly affects the COx microstructure with no swelling and no change in the pore size distribution curve, in accordance with the stability of the two layers of interlayer water molecules in this suction range. Passing from $9 \mathrm{MPa}$ to zero suction allows the placement of a third, or even a fourth layer of water molecules that results in significant changes in the inter-platelets porosity and imultaneous development of saturated cracks.

Drying the specimen at 150 and $331 \mathrm{MPa}$ results in a reduction from 32 to $28-27 \mathrm{~nm}$ of the mean diameter of the pore size distribution curve with the placement of one layer of water molecules, which explain the small differences in microstructure observed at these two suctions. Oven-drying at $105^{\circ} \mathrm{C}$ results in a further decrease to $20 \mathrm{~nm}$ in the mean diameter of the interplatelet porosity, a state compatible with the status of smectite minerals at dry state, with no water layer adsorbed and an interlayer space of $9.6 \AA$.
Finally, the mechanisms of water adsorption along smectites allows to better define the status of water in claystones and shales containing some smectites, with a distinction between the adsorbed water (located within the platelets and made up of two layers strongly bonded along the smectite faces with suctions larger than $9 \mathrm{MPa}$ ) and the free water (located in the inter-platelets porosity, defining the pore pressure and submitted to water transfers). The MIP curve at initial state provides an idea of the proportions of the two types of water, with around $68 \%$ of free inter-platelets water and $32 \%$ of adsorbed intra-platelets water.

\section{Acknowledgements}

The authors are indebted to Andra, the French agency of radioactive waste disposal, who financially supported this research through the PhD thesis of the first author and provided the specimens of Callovo-Oxfordian claystone.

\section{References}

[1] Pham QT, Vales F, Malinsky L, Nguyen Minh D, Gharbi H (2007). Effects of desaturation-resaturation on mudstone. Phys. Chem. Earth 32: 646-655.

[2] Wan M, Delage P, Tang AM, Talandier J (2013). Water retention properties of the Callovo-Oxfordian claystone. Int. J. Rock Mech. Min. Sc. 64: 96-104

[3] Gaucher G, Robelin C, et al. (2004). ANDRA underground research laboratory: interpretation of the mineralogical and geochemical data acquired in the Callovian-Oxfordian formation by investigative drilling. Phys. Chem. Earth 29: 55-77

[4] Yven B, Sammartino S, et al. (2007). Mineralogy texture and porosity of Callovo-Oxfordian claystones of the Meuse/Haute-Marne region (eastern Paris Basin), Mém Soc Géol France, 178: 73-90

[5] Delage P, Marcial D, Cui YJ, Ruiz X (2006). Ageing effects in a compacted bentonite: a microstructure approach. Géotechnique 56 (5): 291-304

[6] Diamond, S. (1970). Pore size distribution in clays. Clays Clay Min. 18, 7-23

[7] Sammartino S, Bouchet A, Prêt D et al. (2003). Spatial distribution of porosity and minerals in clay rocks from the Callovo-Oxfordian formation (Meuse/Haute-Marne, Eastern France)_implications on ionics species diffusion and rock sorption capability. App. Clay Sc. 23 (1-4): 157-166

[8] Boulin PF, Angulo-Jaramillo R, Daian JF et al. (2008). Pore gas connectivity analysis in CallovoOxfordian argillite. App. Clay Sc. 42: (1-2) 276-283

[9] Mooney RW, Keenan AC, Wood LA (1952). Adsorption of water vapor by montmorillonite. II. Effect of exchangeable ions and lattice swelling as measured from X-ray diffraction. J. Am. Chem. Soc. 74: $1371-1374$

[10] Saiyouri N, Tessier D, Hicher PY (2004). Experimental study of swelling in unsaturated compacted clays. Clay Min. 39:469-479 